\title{
ANÁLISE TÉCNICO-JURÍDICA DO LICENCIAMENTO AMBIENTAL E SUA INTERFACE COM A CERTIFICAÇÃO AMBIENTAL ${ }^{1}$
}

\author{
Eder Cristiano Viana², Rosa Maria Miranda Armond Carvalho³, Paulo Rogério Soares de Oliveira ${ }^{3}$, Sebastião \\ Renato Valverde ${ }^{4}$ Thelma Shirlen Soares ${ }^{3}$
}

\begin{abstract}
RESUMO - O objetivo do presente trabalho foi promover uma análise comparativa do licenciamento e da certificação ambiental, para daí extrair uma fundamentação técnica e jurídica que possibilite verificar a interface entre eles. Utilizou-se uma abordagem teórico-metodológica da pesquisa social aplicada e jurídica, através de uma vertente jurídico-dogmática, bem como uma pesquisa dos fundamentos técnicos e sociais, para avaliação dos processos de certificação ambiental. Objetivou-se comprovar a existência de uma nítida interface entre licenciamento e certificação ambiental, embora não se possa admitir a suplantação da atividade estatal ou sequer a modificação das estruturas básicas da certificação. Recomenda-se um diálogo maior entre o Poder Público e as organizações privadas na busca de um desenvolvimento econômico que concretamente visa a sustentabilidade.
\end{abstract}

Palavras-chave: Meio ambiente, gestão ambiental, ISO e normas ambientais.

\section{TECHNICIAN-JURIDICAL ANALYSIS OF THE ENVIRONMENTAL LICENSING AND ITS INTERFACE WITH THE ENVIRONMENTAL CERTIFICATION}

\begin{abstract}
This study aims to carry out a comparative analysis of licensing and environmental certification to extract a technical and juridical basis to verify the interface between them. A theoretical-methodological approach of the applied and juridical social research was utilized from a juridical-dogmatic viewpoint, as well as a research of the technical and social foundations to evaluate the processes of environmental certification. This research aimed to prove the existence of a clear interface between licensing and environmental certification although the replacement of the state action or even the modification of the basic structures of certification cannot be admitted. Further discussion between the public government and private organizations is recommended to pursue an economic development concretely aiming at sustainability.
\end{abstract}

Key words: Enviroment, enviromental administration, ISO, environmental norms.

\section{INTRODUÇÃO}

Os temas certificação e licenciamento ambiental vêm ocupando, atualmente, posição de destaque no meio florestal e de outras atividades que, de alguma forma, possam causar algum impacto ao meio ambiente. A certificação ambiental decorre de uma exigência do mercado; o licenciamento, por outro lado, de intervenção do Poder
Público na atividade privada, com a finalidade de proteção ambiental. Em ambos, no entanto, busca-se agir segundo uma filosofia do desenvolvimento associado à conservação ambiental.

A certificação ambiental revela-se como um instrumento de grande importância para proteção do meio ambiente. Tal fato se soma às preocupações do Poder

1 Recebido para publicação em 16.12.2002.

Aceito para publicação em 9.9.2003.

2 Estudante de Mestrado, Departamento de Engenharia Florestal da Universidade Federal de Viçosa - /UFV, 36570-000 ViçosaMG; ${ }^{3}$ Estudante de Doutorado, Departamento de Engenharia Florestal - UFV; ${ }^{4}$ Prof. do Departamento de Engenharia Florestal - UFV. 
Público, que, de alguma forma, deve valorizar iniciativas de tal natureza. É o que ocorre, por exemplo, com o fomento de pesquisas e investimentos nas chamadas tecnologias limpas.

O papel do Poder Público origina-se da necessidade de uma regulamentação que, atualmente, reveste-se das características de imposição de normas e mecanismos, sobretudo de fiscalização, que interferem na atuação das empresas e de particulares cujas atividades repercutem no meio ambiente, principalmente gerando impactos negativos. Entre os vários instrumentos legais instituídos com este intuito pode-se citar o licenciamento ambiental. Este é praticado no Brasil em vários Estados, por exigência da Constituição Federal e da Lei n ${ }^{\circ}$ 6.938/81, que o elege como instrumento da Política Nacional do Meio Ambiente (PNMA).

Tanto a certificação como o licenciamento ambiental funcionam como meio de proporcionar e garantir o comportamento ambientalmente correto de uma determinada organização, embora possuam fins e princípios diversos.

É neste ponto que se situa a discussão em torno da qual os gestores da iniciativa privada objetivam simplificar o processo de licenciamento ambiental diante dos sistemas de certificação, ou vice-versa, motivados pelo fato de que entre estes existem vários pontos na interface.

O confronto desses dois mecanismos leva aos seguintes questionamentos: por que as empresas já certificadas não são dispensadas do licenciamento? Ou, pelo menos, será que estas não mereceriam um tratamento diferenciado nos processos de licenciamento, tão morosos e onerosos? Não tendem ambos ao mesmo fim? De outro lado, por que a certificação de uma empresa que tem suas atividades licenciadas não é facilitada?

Esses problemas decorrem do alto custo dos processos de licenciamento, associado à sua morosidade $\mathrm{e}$ ao argumento de que o próprio mercado pode se incumbir de eleger, através da certificação ambiental, instrumentos que garantam a credibilidade ambiental das empresas e, assim, a proteção ambiental. Garantia que, para muitos, suplanta a do próprio Poder Público, desgastado pelos processos de corrupção e ineficiência que assolam as estruturas administrativas estatais.

O objetivo deste trabalho foi analisar o instrumento jurídico licenciamento ambiental e sua interface com a certificação ambiental, estabelecendo entre eles um paralelo que possibilite verificar o cabimento ou não da substituição, no todo ou em parte, entre os mesmos.

R. Árvore, Viçosa-MG, v.27, n.4, p.587-595, 2003
Especificamente, buscaram-se respostas aos questionamentos antes apresentados, com vistas a contribuir com a otimização de tais procedimentos, indispensáveis à iniciativa privada.

\section{MATERIAL E MÉTODOS}

A análise empreendida, embora teórica - a conformação dos dois institutos -, possui nítido caráter prático, uma vez que busca solucionar o problema de se empreender esforços para agilizar, facilitar e diminuir os custos dos processos de licenciamento e certificação ambientais para os empreendedores.

Neste trabalho utilizou-se uma corrente teóricometodológica da pesquisa social aplicada e jurídica, por intermédio de uma vertente jurídico-dogmática (Gustin et al., 2001). Isto porque tal corrente trabalha com elementos internos ao ordenamento jurídico, desenvolvendo um raciocínio dedutivo para a sua execução.

Desta forma, foi realizada uma busca na literatura especializada sobre os temas envolvidos e, por fim, travou-se discussão sobre as semelhanças e diferenças, para deste modo chegar-se à conclusão e às possíveis respostas para o problema proposto.

\section{RESULTADO E DISCUSSÃO}

\subsection{Certificação Ambiental}

Uma análise acurada da certificação ambiental e do processo de licenciamento ambiental é imprescindível para que se consiga traçar um paralelo, bem como para identificar a interface entre ambos. Principia-se a análise pela certificação.

A certificação ambiental surge no contexto em que a variável ambiental se insere no campo organizacional da empresa, tanto por uma pressão de mercado quanto pelo desenvolvimento crescente dos movimentos ambientalistas e da pressão das instituições políticas. Assim, passa-se a exigir que as empresas tenham um compromisso efetivo de proteção e conservação da natureza, o que servirá, igualmente, para informar ao mercado sobre a origem do produto e as técnicas de produção.

De fato, a certificação visa atestar o comportamento adequado, do ponto de vista ambiental, de certos empresários e atividades, o que se faz sempre tendo em vista determinadas normas e regras estabelecidas por entidades 
normatizadoras privadas, ou por grupos ou conselhos formados por estas entidades.

Nardelli (2001) afirma, ao discorrer sobre a certificação no setor florestal, que ao buscar uma certificação as empresas estão lançando mão de um instrumento institucionalizado de diferenciação, com o objetivo de informar e garantir ao consumidor e às demais partes interessadas que determinados padrões de desempenho de seu manejo florestal estão sendo atingidos e monitorados. Deve-se salientar ainda que a certificação florestal, segundo Miranda (2002), além de melhorar a imagem institucional das empresas, fornece a elas instrumentos de desenvolvimento e mecanismos de prevenção a impactos ambientais.

Souza (2000) afirma ainda que as normas dos diversos sistemas de certificação ambiental, tais como as normas da série ISO 14000, apresentam oportunidades empresariais e de proteção ambiental. Para tanto, os sistemas de certificação ambiental envolvem as chamadas "auditorias ambientais" e a concessão de "selos ambientais".

Tais sistemas surgiram a partir da década de 90, para cumprir demandas como a ética nos negócios, a responsabilidade social e, principalmente, o desenvolvimento sustentável (Nardelli, 2001). Este último é conceituado como o processo de desenvolvimento que visa trazer ao âmbito econômico a visão de esquemas de desenvolvimento tendentes à satisfação das necessidades da geração presente, sem comprometer a capacidade das gerações futuras, para satisfazer suas próprias necessidades, e não o crescimento econômico indiscriminado (Guzmán, 1998), idéia inicialmente apresentada no Relatório Brundtland, da Comissão Mundial sobre Meio Ambiente e Desenvolvimento: Nosso Futuro Comum, de 1988.

Na verdade, os processos de certificação ambiental almejam conferir à empresa uma imagem que lhe proporcione um diferencial no mercado, bem como mecanismos para efetivar os processos de gerenciamento ambiental nas diversas organizações, comprovando que estas possuem uma atuação que respeita o meio ambiente. Tal conclusão decorre da análise do campo organizacional em que a certificação está inserida, o qual é composto por comerciantes, industriais, ONGs e, no caso das atividades florestais, pelo manejador florestal (Nardelli, 2002).

A apresentação do tema desta forma pode levar à conclusão incorreta de que as empresas preocupam-se somente com sua imagem perante o mercado, atuando em prol do meio ambiente só para efeito da melhoria desta. Se para muitas empresas, em princípio, a certificação possuía tão somente os aludidos objetivos, atualmente, com a institucionalização das preocupações ecológicas e ambientais, passa a existir o maior comprometimento das organizações diante das exigências sociais contemporâneas.

Tal situação define, por sua vez, a importância do certificado ambiental expedido por uma determinada instituição, o que está estritamente relacionado com a sua credibilidade no mercado. Por outro lado, permite, ainda, não se atribuir à certificação um caráter apenas mercadológico. Justificam-se, igualmente, em face das crescentes preocupações sobre o estádio de degradação ambiental no Planeta, as discussões em que as instituições normatizadoras estão inseridas. A importância do tema foi destacada a partir de conferências como a ECO-92, no Rio de Janeiro, que resultou na adoção de várias medidas tendentes à proteção do meio ambiente e também influenciou a adoção do Protocolo de Quioto e a organização das várias rodadas de discussões sobre o estádio atual do clima e dos rumos do desenvolvimento mundial (Itto, 1998).

Os sistemas de certificação florestais, por exemplo, são apresentados como um processo que consiste na avaliação objetiva das operações envolvidas no manejo das florestas, segundo normas ou padrões que obedecem a princípios e critérios aceitos internacionalmente, porém adaptados às condições locais (Nardeli, 2002).

Como exemplos desses sistemas de certificação podem ser citados o FSC (Forest Stewardship Council); as normas da série ISO 14000 da International Organization for Standardization (ISO), conforme seu processo de gestão ambiental; e o CERFLOR, da ABNT (Associação Brasileira de Normas Técnicas), através da NBR 14.789 (Carvalho, 2002). Estes últimos voltados para o setor florestal.

Para obter as certificações ambientais, o sistema se forma a partir do estabelecimento de padrões nacionais ou internacionais, fixados por ONGs, na maioria das vezes, e por instituições independentes, formadas por entidades de vários países, no caso das entidades internacionais, chamadas entidades normatizadoras. Estas diferentes entidades e as instituições privadas de cada país são credenciadas para atestar o cumprimento das normas e dos critérios, previamente estabelecidos.

R. Árvore, Viçosa-MG, v.27, n.4, p.587-595, 2003 
Tais entidades certificadoras mantêm contato com aquelas empresas que objetivam a certificação e realizam vistorias e auditorias ambientais, para atestar o comportamento adequado ambientalmente, para implementação de um sistema de gerenciamento, para adequação do processo produtivo ou para atestar que o produto decorre de um processo que respeita a natureza. Só depois é que as empresas estarão ou não aptas para obter o certificado ambiental.

Há vários sistemas de certificação ambiental, como rotulagem, selo e auditorias ambientais. No Reino Unido, por exemplo, existe a norma BS 7750, nos Estados Unidos, a SGA NSF 110 DA NSF Internacional (Souza, 2000). No Brasil pode-se citar, além dos já apresentados, a certificação agrícola para o setor canavieiro, do Instituto de Certificação e Manejo Florestal e Agrícola - Imaflora/ CAN, associado ao Instituto de Agricultura - CAN, cuja certificação possui grande aceitação no mercado internacional, com o selo socioambiental ECO-O.K. ${ }^{\circledR}$

Esses sistemas de certificação, portanto, objetivam atestar o comportamento ambientalmente correto das empresas, conforme padrões preestabelecidos, seja na produção de um item específico, seja no gerenciamento ambiental da organização. Atualmente, conforme uma visão holística que se tem atribuído à questão ambiental, analisam-se não só os aspectos inerentes à produção, mas também a pesquisa da inter-relação empresa-comunidade, na busca do desenvolvimento sustentável, do ponto de vista socioeconômico. É o que se tem como conseqüência da inauguração de uma racionalidade ambiental, compromissada com um novo paradigma de desenvolvimento (Leff, 2001).

Deve-se ressaltar, portanto, que o principal motor dos processos de certificação está ligado aos aspectos técnico-científicos - no estabelecimento dos critérios de sustentabilidade - associados às expectativas do mercado. Conforme salienta Nardelli (2001), a busca da certificação é um dos caminhos pelos quais a empresa visa obter capacidade competitiva e sobreviver no mercado. É, também, um meio de aproveitamento das oportunidades para aumentar ou manter a eficiência. Portanto, tem, estritamente, a finalidade de atender a objetivos privados, embora se reconheçam os benefícios sociais, diretos ou indiretos, que proporciona.

A certificação ambiental como um mecanismo inerente às práticas comerciais, ainda de maior importância no âmbito internacional, pode ser vista como uma resposta do próprio mercado à incapacidade institucional do Estado em manter mecanismos legais eficientes de proteção ambiental.

Esse fato não permite concluir que a admissão de tais normas implique o desmantelamento da estrutura regulatória governamental, nem evidencia que a base institucional para o tratamento da questão ambiental deva permanecer sob responsabilidade única e exclusiva do mercado (Nardelli, 2001). Embora as entidades certificadoras assumam este papel, atuando com neutralidade - o que lhes proporciona credibilidade -, cuidar das questões ambientais é dever do Poder Público.

\subsection{Licenciamento Ambiental}

O licenciamento ambiental é um procedimento administrativo que, ao analisar as condições para implementação e operação de determinado empreendimento e sua conformidade com a lei, poderá ocasionar a concessão de licença, sujeita ou não a determinados condicionantes, o que é feito pelo Poder Público no exercício de seu poder de fiscalização.

O primeiro aspecto a ser salientado é que o licenciamento ambiental é uma exigência legal, contida especialmente na Lei 6.938/81 e em algumas legislações específicas. É eleito como um dos instrumentos do Estado para o cumprimento dos princípios da Política Nacional do Meio Ambiente. É um procedimento voltado para a compatibilização do desenvolvimento de atividades econômicas necessárias ao homem e a conservação do meio ambiente, cujo objetivo primordial é a promoção do bem-estar social.

Antunes (2001) salienta que através do licenciamento a Administração Pública estabelece condições e limites para o exercício de determinadas atividades. Complementando, afirma que somente serão permitidas práticas e condutas cujos impactos ambientais estejam compreendidos dentro dos padrões fixados, ou quando estes forem de pequena monta. Devem ser apontadas, também, medidas a serem adotadas com vistas a mitigar estes efeitos negativos inevitáveis da atividade.

O licenciamento ambiental, segundo Alonso Jr. (2002), vem a ser um procedimento colocado à disposição dos interessados, por meio do qual o Poder Público, mediante controles prévios - licenças -, verifica a regularidade técnica e jurídica de determinadas atividades, efetiva ou potencialmente poluidoras, de forma a compatibilizar o desenvolvimento econômico e a proteção dos recursos naturais. 
Embora essa adequação do exercício da atividade seja também competência de outros procedimentos administrativos, como a fiscalização administrativa, a importância do licenciamento reside no fato de se tratar de um controle prévio da atividade e que, portanto, constitui um obstáculo legal ao início da atividade considerada nociva, sob o ponto de vista ambiental.

O procedimento do licenciamento ambiental possui algumas fases, quais sejam, a licença prévia, de instalação e de operação. Cada qual é responsável por possibilitar ao particular que a solicita proceder nos termos determinados pelo Poder Público, para cada uma das etapas em que atividade está sendo implementada.

Desse modo, entendido o licenciamento como um procedimento administrativo, ao final será expedido um ato administrativo, corporificado num documento, que é a licença ambiental ou uma autorização. Estes são os documentos exigidos para que se dê início à atividade e seja realizada sua instalação ou operação. É o "certificado público" que a Administração Pública confere ao empreendedor, atestando que todas as normas ambientais estão sendo obedecidas e que os padrões técnicos exigidos pelo Poder Público estão sendo cumpridos.

\subsubsection{O Licenciamento Ambiental e o Poder de Polícia da Administração Pública}

O licenciamento ambiental, por ser uma atividade estatal tipicamente administrativa, reveste-se de determinados atributos, que fundamentam as distinções entre as atividades desenvolvidas pelos órgãos públicos e pelas certificadoras privadas.

Primeiro, é preciso ficar claro que o licenciamento ambiental é exercido por um órgão público competente. A competência em matéria ambiental é o que fixa o papel e os poderes do órgão ambiental. Refere-se, na verdade, à competência de fiscalização na área ambiental, porque está ligado ao exercício do que se chama "poder de polícia” da Administração Pública.

O poder de polícia no Brasil vem legalmente definido no Art. 78, do Código Tributário Nacional. É entendido como a atividade do Estado consistente em limitar o exercício dos direitos individuais em benefício do interesse público, este relacionado aos mais variados setores da sociedade, como segurança, moral, saúde, meio ambiente, defesa do consumidor, patrimônio cultural e direito de propriedade. Daí a divisão da polícia administrativa em vários ramos: polícia de segurança, das florestas etc. (Di Pietro, 1998).

É preciso ressaltar, ainda, que a polícia administrativa atua principalmente de forma preventiva, possuindo como atribuição primordial atuar na informação, ao contrário de um comportamento punitivo, aplicando penalidades aos infratores.

Esse poder de polícia em matéria ambiental tem como finalidade a manutenção da ordem pública, na medida em que é atribuição e dever do Poder Público fiscalizar e regulamentar a atuação dos particulares que, de alguma forma (efetiva ou potencialmente poluidoras), interfiram no equilíbrio ambiental. Hoje, pode-se referir à existência de uma ordem pública ambiental que visa estabelecer um mínimo de salubridade ambiental (Antunes, 2002).

Ainda segundo o autor, o poder de polícia e, por sua vez, o licenciamento ambiental, como sua forma de exteriorização, reveste-se de algumas características. A primeira delas é a auto-executoriedade, isto é, o Poder Público age por vontade própria, independentemente de intervenção de qualquer outro poder estatal. Basta-lhe seguir a lei, de forma que o procedimento seja cumprido, sem extrapolá-lo.

Apresenta ainda como característica o fato de o poder de polícia ser uma atividade negativa (Di Pietro, 1998), ao contrário dos serviços públicos, que são uma atividade positiva, uma realização de algo. Isto é, o exercício daquele impõe ao particular uma abstenção, uma obrigação de não-fazer alguma coisa, de forma que, mesmo quando aparentemente exige a realização de uma tarefa, como promover o devido licenciamento ambiental, objetiva evitar um dano oriundo do mau exercício do direito individual. Deve-se sempre atentar para a necessidade, a proporcionalidade e a eficácia da abstenção imposta, sob pena de ferir o direito individual limitado.

O licenciamento ambiental possui ainda uma outra característica. Advém da competência dos poderes públicos para o exercício do poder de polícia em matéria ambiental. Na verdade, isto significa dizer que o exercício de tais poderes pelos entes estatais é privativo.

As atribuições deferidas à União, aos Estadosmembros, aos municípios e ao Distrito Federal (DF) em matéria ambiental são de duas ordens: legislativa e administrativa. A primeira é aquela que diz qual destes terá competência para editar leis, visando a tutela do meio ambiente. A última delimita a atuação na execução dos atos e das medidas para o cumprimento das leis. Limita

R. Árvore, Viçosa-MG, v.27, n.4, p.587-595, 2003 
o exercício do poder de polícia em matéria ambiental, o poder normatizador e fiscalizador.

$\mathrm{O}$ poder de fiscalizar, estabelecer regulamentos e padrões e zelar pelo seu cumprimento é competência administrativa, que nos termos do Art. 23, da CF, atribui a todas as pessoas políticas que, de forma específica, ocupam-se dos assuntos do interesse de cada uma, nacional, regional e local, respectivamente.

Não seria razoável, como bem salienta Machado (1999), que um particular exercesse o poder de fiscalizar e regulamentar a atitude de outro particular, pois não se estaria atendendo aos fins de interesse social. Na verdade, estes fundamentos orientaram a inserção de tal princípio na própria Constituição. O autor também salienta que esse poder não só não pode ser concedido a um particular, como também a Administração não pode se despojar de suas responsabilidades neste domínio.

\subsection{Interface entre o Licenciamento e a Certificação Ambiental}

\subsubsection{Certificação versus Licenciamento Ambiental}

A análise empreendida sobre a certificação e o licenciamento ambiental já permite extremar os dois instrumentos, seus objetivos e suas principais características. É a partir destes conceitos básico que se pode elaborar o seguinte quadro comparativo.

\begin{tabular}{|c|c|c|}
\hline $\begin{array}{l}\text { Elemento de } \\
\text { Comparação }\end{array}$ & Certificação & Licenciamento \\
\hline Objetivos & $\begin{array}{l}\text { Atestar comportamento menos nocivo ao } \\
\text { meio ambiente e, ou, promover uma } \\
\text { atuação do particular conforme padrões } \\
\text { técnicos de conservação ambiental. }\end{array}$ & $\begin{array}{l}\text { Atestar comportamento menos nocivo ao meio } \\
\text { ambiente e, ou, promover uma atuação do particular } \\
\text { conforme padrões técnicos de conservação } \\
\text { ambiental. }\end{array}$ \\
\hline Atuação & $\begin{array}{l}\text { Promove a verificação da compatibilidade } \\
\text { da atividade com conservação ambiental, } \\
\text { visando equalizar desenvolvimento } \\
\text { econômico e sustentável. }\end{array}$ & $\begin{array}{l}\text { Promove a verificação da compatibilidade da } \\
\text { atividade com conservação ambiental, visando } \\
\text { equalizar desenvolvimento econômico e sustentável. }\end{array}$ \\
\hline $\begin{array}{l}\text { Formação do } \\
\text { processo/sistema }\end{array}$ & $\begin{array}{l}\text { O sistema constitui-se através de } \\
\text { prescrições normativas que devem ser } \\
\text { obedecidas por aquele que procura obtê-la. } \\
\text { São regras cujos cumprimento e } \\
\text { observância são pré-requisitos para a } \\
\text { expedição do certificado. }\end{array}$ & $\begin{array}{l}\text { É procedimento administrativo formado por } \\
\text { conjunto de prescrições normativas que devem } \\
\text { obedecidas por aquele que requer o licenciamento. } \\
\text { Devem ser observados procedimentos e normas para } \\
\text { a expedição da licença. }\end{array}$ \\
\hline A quem compete & $\begin{array}{l}\text { É desenvolvida por particulares, visando } \\
\text { atender a interesses também particulares. }\end{array}$ & $\begin{array}{l}\text { É atividade desenvolvida pelo Poder Público, } \\
\text { possibilitando o desenvolvimento de certa atividade } \\
\text { privada. Visa sempre o bem público, comum. }\end{array}$ \\
\hline Natureza da normas & $\begin{array}{l}\text { As regras e os critérios que prescrevem os } \\
\text { procedimentos para a certificação } \\
\text { ambiental são normas de adesão } \\
\text { voluntária. }\end{array}$ & $\begin{array}{l}\text { Decorre de exigência legal, isto é, são normas de } \\
\text { caráter obrigatório, editadas e válidas em todo o } \\
\text { território nacional. }\end{array}$ \\
\hline $\begin{array}{l}\text { Quem elabora as } \\
\text { normas }\end{array}$ & $\begin{array}{l}\text { As normas são elaboradas por entidades } \\
\text { privadas (entidades normatizadoras), } \\
\text { sendo também privadas aquelas entidades } \\
\text { encarregadas da verificação e auditoria } \\
\text { para a expedição dos certificados } \\
\text { ambientais (entidades certificadoras) }\end{array}$ & $\begin{array}{l}\text { São normas elaboradas pelas pessoas de direito } \\
\text { público interno competentes (União, Estados, } \\
\text { municípios e DF). }\end{array}$ \\
\hline Origem & $\begin{array}{l}\text { Decorre da atuação particular em virtude } \\
\text { de uma exigência do mercado. }\end{array}$ & $\begin{array}{l}\text { Exercício do poder de polícia do Estado, por força } \\
\text { dos deveres e das competências constitucionais. }\end{array}$ \\
\hline Momento de atuação & $\begin{array}{l}\text { Atuação posterior, quando em } \\
\text { funcionamento a atividade. }\end{array}$ & $\begin{array}{l}\text { Atuação preventiva, condicionando o exercício da } \\
\text { atividade conforme a lei. Pode haver atuação } \\
\text { posterior, se a atividade já está em funcionamento. }\end{array}$ \\
\hline
\end{tabular}




\subsubsection{Necessidade de Compatibilizar Licenciamento Ambiental e Certificação}

Feita a comparação entre o licenciamento e a certificação ambiental, há de se retomar os questionamentos feitos anteriormente: por que as empresas já certificadas não são dispensadas do licenciamento? Ou, pelo menos, será que estas não mereceriam um tratamento diferenciado nos processos de licenciamento, tão morosos e onerosos, em prol da atividade econômica a ser desenvolvida? Não tendem ambos ao mesmo fim?

Quando se diz que o licenciamento e a certificação ambiental possuem objetivos semelhantes não se afirma, necessariamente, que ambos têm a mesma finalidade. Primeiro, porque o licenciamento ambiental é exigência da lei, tendo em vista o bem comum. Quando um empreendedor procura se certificar, busca um instrumento que ateste adequação do empreendimento aos parâmetros ambientais mais aceitos, o que será um diferencial no âmbito do mercado que beneficia tão somente o empresário, sem qualquer interesse público direto, embora se reconheça existirem benefícios indiretos para toda sociedade.

Saliente-se, ainda, que os critérios utilizados para apreciação da adequação do empreendimento à conservação ambiental são diversos. Um é ditado pela lei, no caso do licenciamento, enquanto o outro, por organismos e empreendedores particulares, embora todos tenham o seu suporte técnico.

Constata-se que, em termos de certificação, um dos princípios a serem observados é o cumprimento da legislação, notadamente a ambiental. Isto justificaria, em princípio, levar em consideração a certificação ambiental da atividade que já a possui e que busca se licenciar, como seria o caso de uma licença de operação corretiva. Tal fato decorre ainda da afirmação de que há na certificação um espectro maior de atividades contempladas, se comparada ao processo de licenciamento da mesma atividade, podendo haver, igualmente, justaposição destes aspectos.

Neste ponto é que parece estar o questionamento sobre a necessidade de se licenciar atividades que já obtiveram a certificação. Atestar a possibilidade de uma suprimir a outra é contrariar as peculiaridades de ambos os instrumentos.

A certificação é um instrumento privado, envolvendo interesses também privados daqueles que a buscam. De fato, ligá-la a um imperativo público seria um equívoco, pois ela estaria assumindo papel que não lhe é próprio. Os interesses públicos e coletivos preservados pelo Estado envolvem valores que visam compatibilizar o desenvolvimento econômico e a nãoformação de obstáculos ao desenvolvimento de atividades pelos particulares - do ponto de vista de mercado, por exemplo -, preservando o interesse de todos; atribuição que não deve ser conferida às certificadoras. Estas devem, neste sentido, preservar sua isenção e credibilidade, o que não seria possível caso sua atuação fosse realizada de forma diversa da atual, uma vez que o Poder Público, em última análise, tenderá sempre para a preservação do interesse coletivo.

Outro obstáculo em se admitir a substituição do licenciamento e da certificação, ou vice-versa, é o fato de o licenciamento ser prévio e a certificação ser realizada quando o empreendimento já se encontra em funcionamento. Aceitar a possibilidade de a certificação substituir a licença é subverter seus princípios e sua sistemática. É ainda querer que o licenciamento ambiental seja reformulado em sua dinâmica legal, ou que a certificação seja esvaziada de sua função principal, que é o atestado de uma conduta ambientalmente correta para o mercado.

Afastando-se a possibilidade de aceitar, de acordo com a legislação brasileira atual, a substituição do licenciamento pela certificação, deve-se lembrar ainda do disposto no Art. 23, da CF, que prescreve a privatividade do exercício do poder de polícia ambiental para os órgãos estatais. São, assim, indelegáveis a particulares, de modo que é um papel do Estado exercer o poder de polícia ambiental. Não se pode, simplesmente, subtrairlhe tais deveres. Tal fato somente seria possível mediante instauração de uma nova ordem constitucional.

Salienta-se que no processo de licenciamento, no entanto, a licença é concedida com prazo determinado, podendo ser o seu processo de renovação apenas facilitado, caso a atividade já esteja certificada. Contudo, algumas condições devem ser observadas para que não se fira a lei.

O primeiro passo é a inserção da certificação como elemento ou requisito contido na própria lei. A dificuldade apresenta-se porque tal fato somente seria possível se as empresas certificadoras fossem submetidas à apreciação do Estado, que, assim, atestaria que o certificado expedido por determinada certificadora poderia, em alguns dos requisitos, suprimir etapas do procedimento de licenciamento. Seria uma espécie de "licenciamento da certificadora".

R. Árvore, Viçosa-MG, v.27, n.4, p.587-595, 2003 
Esse novo procedimento que seria instituído, na verdade, tem fundamento no respeito à lei e nos princípios que informam os procedimentos administrativos, como o da competência administrativa em matéria ambiental.

Em segundo lugar, porque seria necessária a intervenção do Estado em defesa da soberania, que embora hoje mitigada ainda é a base da constituição dos Estados independentes, já que as normas de certificação ambiental são formuladas por grandes organismos multilaterais, de acordo com padrões internacionais.

Nesse caso, mesmo sendo tais normas aplicadas e adaptadas por certificadores nacionais, estes têm objetivos privados, como se afirmou. Admitir suplantar o processo de licenciamento pela certificação seria, na verdade, substituir o Estado pelos particulares, o que é vedado expressamente pelo atual sistema normativo pátrio.

Endossar essa possibilidade seria vergastar a soberania. O Estado estaria abrindo mão de seu poder soberano - e de seus deveres -, em prol de entidades privadas, muitas estrangeiras, afrontando-se a Constituição (Art. $1^{\circ}$, I e art. $4^{\circ}$ ). Seria a realização de atos da administração por organismos externos.

O que se deve defender, como próprio imperativo do Estado Democrático, é uma cooperação entre o ente público licenciador e os organismos privados de certificação, sem que um suprima a atividade do outro.

$\mathrm{Na}$ verdade, o que se deve considerar é que a observância dos procedimentos legais e, portanto, a obtenção do licenciamento funcionam como um facilitador do processo de certificação, que tem como um dos primeiros princípios o cumprimento da legislação onde está em funcionamento a atividade. Do ponto de vista prático, ao adotar as medidas ditadas pelo licenciamento ambiental a empresa estará mais apta a obter a certificação.

\section{CONCLUSÕES}

Portanto, pode-se concluir que existe uma nítida interface entre licenciamento e certificação ambiental, cuja verificação pode partir dos objetivos de ambos, tendendo, em última análise, à conservação do meio ambiente e de serem meios para a condução dos processos produtivos sob o prisma do desenvolvimento sustentável,

R. Árvore, Viçosa-MG, v.27, n.4, p.587-595, 2003 o que circunscreve a sua importância no âmbito econômico e social.

Licenciamento ambiental pode, então, ser entendido como um guia, auxiliando na busca do planejamento de uma determinada organização, porque é uma atividade prévia. É uma obrigação legal que deixa clara as medidas a serem atingidas pela empresa, quando interfere no meio ambiente.

Por outro lado, é também instrumento de intervenção do Poder Público na atividade econômica e de execução de sua política ambiental. É este o papel do poder de polícia do Estado que visa garantir qualidade de vida.

A certificação ambiental, por sua vez, concretizase como uma forma de atestar que o controle e o planejamento exercido dentro de uma determinada organização é eficiente na busca de seus objetivos, funcionando como padrão de referência para adequação dos processos e do gerenciamento para a melhor atuação do ponto de vista ambiental. São normas voluntárias, privadas, previamente conhecidas.

Se a influência para o surgimento da certificação ambiental está nas exigências de mercado, tal fato não lhe empresta significado pejorativo. Ao contrário, pode ser identificada como resposta a um anseio social, como decorrência da evolução da sociedade e da maior exigência dos próprios consumidores, demonstrando suas expectativas das organizações que as cercam.

A título de recomendação, portanto, há de se considerar o fato de não haver possibilidade, conforme o ordenamento jurídico brasileiro atual, de supressão do licenciamento pela certificação, ou, pelas razões já expostas, desta por aquele.

Embora se reconheçam tais aspectos, há de se empreender esforços para a modificação da situação atual. O licenciamento e a certificação são instrumentos de um mesmo processo, isto é, ambos devem ser usados para facilitação da atuação das empresas no que se refere aos aspectos ambientais e sociais. Devem, portanto, atuar o Poder Público e as entidades certificadoras de forma harmônica. Aquele, primoridialmente, não deve atuar de forma somente punitiva, exigindo destas uma atitude de comprometimento com a fixação de critérios técnicos para um desenvolvimento em bases sustentáveis.

Há uma flagrante necessidade de flexibilizar o processo de licenciamento ambiental e de facilitar o diálogo entre os certificadores e o Poder Público, para 
que tanto a empresa quanto a sociedade possuam menores custos e mais agilidade nos sistemas de certificação e de licenciamento.

Um meio pelo qual se pode dar esta cooperação é a existência, na lei, do reconhecimento da atuação das certificadoras, que deveriam promover uma atuação conforme as exigências do licenciamento.

Dessa forma, poderia se empreender uma troca de informações, o que possibilitaria, por exemplo, uma empresa já licenciada estar mais adiantada no processo de certificação, assim como, para alguns casos restritos, ser facilitado o processo de licenciamento de uma atividade já certificada.

\section{REFERÊNCIAS BIBLIOGRÁFICAS}

ANTUNES, P. B. Direito Ambiental. 5.ed. Rio de Janeiro: Lumen iuris, 2001. 657 p.

ALMEIDA, J. R.; MELLO, C. S.; CAVALCANTI, Y. Gestão ambiental - planejamento, avaliação, implantação, operação e verificação. Rio de Janeiro: Thex, 2001. 259 p.

ALONSO JR., H. Da competência para o licenciamento ambiental. In: Fink, D.R., Alonso JR., H., Dawalibi, M. Aspectos jurídicos do licenciamento ambiental. 2.ed. Rio de Janeiro: Forense, 2002. p. 38-50.

CARVALHO, R. C. N. Palestra: Certificação Florestal: aspectos teóricos e acadêmicos. Proferida no III Seminário de Gestão Integrada e Certificação Florestal, 9 a 11.10.2002, no Auditório da Biblioteca Central da Universidade Federal de Viçosa. Realização: Departamento de Engenharia Florestal- DEF.

COMISSÃO MUNDIAL SOBRE MEIO AMBIENTE E DESENVOLVIMENTO - CMMA. Nosso Futuro

Comum. Rio de Janeiro: Fundação Getúlio Vargas, 1988.

DI PIETRO, M. S. Z. Direito Administrativo. 9.ed. São Paulo: Atlas, 1998. 566 p.

FINK, D. R.; ALONSO JÚNIOR, H.; DAWALIBI, M. Aspectos jurídicos do licenciamento ambiental. 2.ed. Rio de Janeiro: Forense, 2002. 245 p.
GUSTIN, M. B. S.; DIAS, M. T. F. Curso de iniciação à pesquisa jurídica e à elaboração de projetos (Re)pensando a pesquisa científica: teoria e prática. 3.ed. Belo Horizonte: NIEPE - Universidade Federal de Minas Gerais/Faculdade de Direito. 2001. 199 p.

GUZMÁN, E. S. Origem, Evolução e Perspectivas do Desenvolvimento Sustentável. In: ALMEIDA, J.; NAVARRO, Z. (Orgs.). 2.ed. Reconstruindo a agricultura - idéias e ideais na perspectiva do desenvolvimento sustentável. Porto Alegre: Editora UFRGS, 1998. p. 19-32.

ITTO. Actualidad florestal tropical. Boletín de la Organización Internacional de las Maderas Tropicales para fomentar la conservación y el desarrollo sostenible de los bosques tropicales, 1998, v. 6, n. 4 .

LEFF, E. Saber Ambiental - sustentabilidade, racionalidade, complexidade e poder. [Trad. Lúcia Mathilde Endlich Orth]. Própolis: Vozes, 2001. 343 p.

MACHADO, P. A. L. M. Direito ambiental brasileiro. 7.ed. São Paulo: Malheiros, 1998. 894 p.

MIRANDA, M. C. De olho no meio ambiente. Disponível em <http://www.ecolatina.com.br/br/artigos/cert_ambiental/ cert_amb_05.asp>. Acesso em 12 outubro 2002.

NARDELLI, A. M. B. Sistemas de Certificação e Visão de Sustentabilidade no Setor Florestal Brasileiro. Viçosa: UFV, 2001. 212 p. Tese (Doutorado em Ciência Florestal) Universidade Federal de Viçosa, 2001.

NARDELLI, A. M. B. Palestra: Procedimentos para certificação: o processo de certificação florestal pelo FSC Proferida no III Seminário de Gestão Integrada e Certificação Florestal, 9 a 11.10.2002, no Auditório da Biblioteca Central da Universidade Federal de Viçosa. Realização: Departamento de Engenharia Florestal- DEF.

SOUZA, R. S. Entendendo a questão ambiental - temas de economia, política e gestão do meio ambiente. Santa Cruz do Sul: EDUNISC, 2000. 461 p. 